\title{
Topical corticosteroid phobia in parents of pediatric patients with atopic dermatitis: a multicentre survey
}

\author{
Maya El Hachem ${ }^{1}$, Francesco Gesualdo ${ }^{2^{*}}$ D, Giampaolo Ricci ${ }^{3}$, Andrea Diociaiuti ${ }^{1}$, Loredana Giraldi ${ }^{1}$, \\ Orsola Ametrano ${ }^{4}$, Corrado Occella ${ }^{5}$, Anna Belloni Fortina ${ }^{6}$, Mirella Milioto ${ }^{7}$, Fabio Arcangeli ${ }^{8}$, Oriana Simonetti ${ }^{9}$, \\ Simona Giancristoforo ${ }^{1}$, Elisabetta Calamelli ${ }^{3}$, Carlo Mazzatenta ${ }^{10}$ and Iria Neri ${ }^{11}$
}

\begin{abstract}
Background: Families of children affected with atopic dermatitis (AD) often report fear and anxiety regarding treatment with topical corticosteroids (TCS), which may lead to reduced compliance. The objective of our study was to measure, through a standardized questionnaire, fear of TCS in families of pediatric patients with AD and to identify items associated with fear.

Methods: Families of pediatric patients with AD were enrolled in 9 Italian centers of pediatric dermatology. Enrolled parents were invited to fill in a questionnaire including questions on sociodemographic and clinical characteristics and 3 sets of questions on corticosteroid phobia (general fear, specific fears, behaviours regarding TCS). Determinants of the level of general fear were investigated through multivariable analysis.

Results: A total of 300 outpatients with AD were enrolled. Most parents (80\%) had a high instruction level. Eighty-one percent reported to have a certain amount of fear of TCS. At the multivariable analysis, fear of TCS was associated with the following items: believing that TCS treatment advantages do not overweight disadvantages $(P=0.011)$; believing that TCS may be dangerous independently from the specific side effect $(P<0.001)$. Moreover, TCS fear was associated with fear of applying too much cream $(P=0.001)$.
\end{abstract}

Conclusion: TCS phobia is widespread among Italian families of children with AD. Fear of TCS is associated with fear of applying too much cream, thus increasing the risk of poor compliance and treatment failure. Therapeutic education of families on the use of TCS should be implemented.

Keywords: Atopic dermatitis, Topical corticosteroids, Children, Corticophobia

\section{Background}

Atopic dermatitis (AD) is a common chronic, pruritic, inflammatory skin disease, mostly affecting children, with heterogeneous lifetime prevalence figures, ranging worldwide from 8 to 18\% [1]. Although its exact pathogenesis still remains unclear, it is well established that $\mathrm{AD}$ depends on a combination of genetic and environmental factors. In patients with $\mathrm{AD}$, a genetically determined alteration of the skin barrier allows penetration of environmental factors,

\footnotetext{
* Correspondence: f.gesualdo@gmail.com

${ }^{2}$ Multifactorial Disease and Complex Phenotype Research Area, Bambino Gesù Children's Hospital IRCCS, Rome, Italy

Full list of author information is available at the end of the article
}

which are linked to a local - and systemic - immune dysregulation [2-4]. Taking into account the inflammatory nature of the disorder and the immune-based pathogenesis of the clinical picture (pruritus, skin hyperreactivity), topical corticosteroids (TCS) have always been the cornerstone of the treatment of AD [4]. Appropriate use of TCS is characterized by a high efficacy, with reduced disease relapsing, and by a low incidence of local and systemic side effects $[5,6]$. Nevertheless, it is very common, in clinical practice, to detect fear and anxiety regarding safety of TCS both among patients affected with $\mathrm{AD}$ and their families and among health care professionals $[7,8]$. Such attitude towards TCS treatment, named TCS phobia, may lead to poor adherence to therapy and consequent treatment failure. 
With the present multicenter study, we investigated prevalence and determinants of steroid phobia in a large group of Italian families of pediatric patients affected by AD.

\section{Methods}

\section{Study design}

This is a multicenter, cross-sectional study conducted in the dermatology units and general pediatric units of 9 pediatric centers located in 9 Italian cities (Ancona, Bologna, Cesena, Genoa, Lucca, Naples, Padova, Palermo, Rome, Bologna). The included centers represent some of the main Italian centers for pediatric dermatology.

From September 2013 to September 2014, families of pediatric patients with $\mathrm{AD}$ consulting for the first time at one of the above mentioned centers were consecutively enrolled. Inclusion criteria were age $<18$ years and a diagnosis of $\mathrm{AD}$. Exclusion criteria were presence of contraindications to the use of TCS (i.e. previous sensitization to TCS, active viral illness) and presence of other forms of dermatitis.

Prior to enrolment, one caregiver was asked to sign an informed consent to the study.

The study was approved by the Bambino Gesù Children's Hospital Ethical Committee (coordinator center) and by the Ethical Committees of all the other involved hospitals.

\section{Questionnaire}

At enrolment, a self-filling questionnaire was given to one of the caregivers attending the patient.

The questionnaire included items on sociodemographic characteristics, previously identified atopic conditions, symptom duration, reason for the outpatient visit, clinical characteristics and SCORAD index at visit, quality of life assessment (DLQI), treatment prescriptions, previous therapeutic education.

Finally, the questionnaire included a standardized set of questions on fear of corticosteroids [7], divided in 3 sections.

In the first section, fear of TCS was investigated, based on a 10-point visual analogue scale (VAS).

In the second section, specific fears and beliefs were investigated through 21 items. The level of agreement to each item was measured through a 4-point Lickert-scale.

In the third section, frequency of parents' behaviours regarding TCS treatment was investigated through 10 items based on a 4-point Lickert-scale.

\section{Clinical parameters}

AD was diagnosed according to Hanifin e Rajka criteria [9]. Severity of AD was assessed through the SCORAD index [10]. Pruritus was evaluated daily for a week after enrolment using the VAS score: from 0 (for no itch) to 10 (for maximum unbearable itch).

\section{Statistical methods}

We estimated a sample size of 302, based on an expected prevalence of TCS phobia of $80 \%$, with a $\pm 5 \%$ precision level and a 97\% confidence interval.

The VAS scale used for expressing fear of corticosteroids was translated into categories as follows: $0-1$ : Not at all; $2-$ 3: A little; 4-6: Moderately; 7-8: A lot; 9-10: Very much.

The ordinal qualitative variables (based on the 4-point Lickert scale) of the second and third section of the questionnaire were converted into quantitative, defined as a score ranging from 0 to 3 (0 representing a completely negative attitude towards TCS, 3 representing a completely positive attitude).

Additionally, we classified each item of the second and third part of the questionnaire into one category among efficacy, safety, compliance and quality of life. We then created 4 new "synthetic" variables, named after these categories. The value of the new variables was the sum of the scores of the items in each category, normalized to 100 .

Proportions were calculated excluding missing values. Results of the descriptive analysis are reported as mean and SD or median and range as appropriate.

We performed a univariate analysis through simple linear regression to investigate factors associated with TCS fear, among the following: sociodemographic variables (child's age and sex, respondent's level of instruction); comorbidities (celiac diseases, thyroid diseases, asthma, allergic rhinitis, food allergy); clinical data including age at $\mathrm{AD}$ diagnosis, $\mathrm{AD}$ duration, $\mathrm{AD}$ evolution, $\mathrm{AD}$ treatment (emollients, systemic corticosteroids, topic TCS, systemic immunosuppressants, topic immunosuppressants, diet), SCORAD, median weekly pruritus, DQLI; having received therapeutic education; each item of the second and third section of the questionnaire and each of the synthetic variables (efficacy, safety, compliance and quality of life).

After checking for multicollinearity, multiple linear regression was used to create two multivariable models. Both models included fear of TCS as the dependent variable, and, as independent variables, those significantly associated with fear of TCS $(p<0.05)$ at the univariate analysis. The first model included only the single items of the questionnaire (that were significantly associated with the outcome at the univariate analysis). The second model included the synthetic variables. Normality was verified with ShapiroWilk test. Results were considered statistically significant with $p<0.05$. Statistical analysis was performed using Stata 11.

\section{Results}

\section{Patients' characteristics}

We consecutively enrolled a total of 300 patients with AD. Sociodemographic characteristics are shown in Table 1. Median age of patients was 3 years. 144/300 patients (48\%) were females. 
Table 1 Patients' demographic and clinical characteristics

\begin{tabular}{|c|c|c|}
\hline Females (n, \%) & 143 & 47,7 \\
\hline Age (median, range) & 3 & $0.2-17$ \\
\hline Comorbidity (n, \%) & 83 & 27,7 \\
\hline celiac disease & 4 & 1,3 \\
\hline diabetes & 0 & 0,0 \\
\hline thyreopathy & 2 & 0,7 \\
\hline asthma & 32 & 10,7 \\
\hline rhynitis & 30 & 10,0 \\
\hline food allergy & 10 & 3,3 \\
\hline other & 16 & 5,3 \\
\hline Years of age at AD diagnosis (median, range) & 0,4 & $0-13$ \\
\hline AD duration in years (median, range) & 1,8 & $0-15$ \\
\hline \multicolumn{3}{|l|}{ Disease evolution (n, \%) } \\
\hline stable & 43 & 14,3 \\
\hline periodic relapses & 164 & 54,7 \\
\hline worsening & 68 & 22,7 \\
\hline improving & 29 & 9,7 \\
\hline irregular & 21 & 7,0 \\
\hline \multicolumn{3}{|l|}{ Treatment (n, \%) } \\
\hline moisturizers & 241 & 84,0 \\
\hline topical steroids & 236 & 82,2 \\
\hline systemic steroids & 56 & 19,5 \\
\hline topical immunosuppressants & 31 & 10,8 \\
\hline systemic immunosuppressants & 10 & 3,5 \\
\hline diet & 81 & 28,2 \\
\hline other & 31 & 10,8 \\
\hline \multicolumn{3}{|l|}{$\operatorname{SCORAD}(n, \%)$} \\
\hline mild & 114 & 39,7 \\
\hline moderate & 125 & 43,6 \\
\hline severe & 52 & 18,1 \\
\hline Therapeutic education (n, \%) & 201 & 67 \\
\hline
\end{tabular}

A large proportion of respondent caregivers had a high education level (80\% had a high school or university degree).

Twenty-seven percent of the included patients had comorbidity, mainly asthma or allergic disorders (allergic rhinitis or food allergy).

Regarding $\mathrm{AD}$, in most cases, the disease had been diagnosed during the first year of life (median age at AD diagnosis: 5 months), and the median $\mathrm{AD}$ duration at enrolment was 1.8 years. Most patients had a moderate-severe $\mathrm{AD}$ (61.7\%). The mean pruritus score was 5 (SD: 2).

A total of 287 patients were taking a treatment for $\mathrm{AD}$ at enrolment. A large proportion of patients were on topical steroids (82.2\%), while $84 \%$ were on moisturizers. Concerning other therapies, 56 patients were (19.5\%) on systemic steroids, $31(10.8 \%)$ on topical immunosuppressants and 10
(3.5\%) on systemic immunosuppressants. Almost 30\% of patients were treated with an elimination diet. Two thirds of respondents had received therapeutic education, either continuous or occasional.

Mean DLQI score was 3.

\section{Descriptive and multivariate analysis}

Overall, a high proportion of patients reported having fears regarding TCS treatment: at the VAS scale, "No fear at all" was reported by $18.8 \%$ of the enrolled patients only (A little: 26.4\%, Moderately: 36.8\%; A lot: 13.7\%; Very much: $4.3 \%)$. Responses to the other questionnaire items are reported in (Table 2).

The multivariable analysis identified few items significantly associated with fear of TCS treatment: believing that TCS treatment advantages do not overweigh disadvantages $(P=0.011)$; believing that TCS may be dangerous independently from the specific side effect $(P<0.001)$; moreover, TCS fear was associated with fear of applying too much cream $(P=0.001)$. Results of univariate and multivariate analyses are reported in Additional file 1.

When subgrouping the items into categories, items concerning safety were more associated with fear compared with items concerning efficacy, compliance or quality of life.

\section{Discussion}

In the present study, we show that, in Italy, fear of TCS is very common among families of pediatric patients affected with $\mathrm{AD}$.

We investigated corticophobia in an exclusively pediatric population. Only few previous studies on TCS phobia have been conducted on a population of children [11-14].

According to our results, fear of TCS is not motivated by specific reasons: most respondents reported that, according to them, TCS are dangerous independently from the specific side effects, and the treatment disadvantages are not balanced by its advantages. In previous studies, the predominant concerns about TCS were cutaneous side-effects and failure to thrive $[7,15,16]$.

Old generation TCS had a high systemic absorption rate, especially in children $[17,18]$. Therefore, their long-term or inadequate use commonly caused a variety of local and systemic side effects, including folliculitis, erythema, reduced skin thickness and/or skin atrophy, striae rubrae, Cushing-like syndrome [19]. Such side effects are still stigmatized in the perception of the patients regarding this type of drug, despite the excellent safety profile of new generation TCS $[19,20]$. Moreover, when appropriately used, new generation TCS are highly effective: they reduce inflammation, itching and relapse rate, thus dramatically improving the quality of life of the patients and their families.

Our study also shows that fear of TCS is related to the fear of applying too much cream. Thus, corticophobia may trigger a vicious circle leading to treatment failure: 
Table 2 Response to questions on TCS specific fears and on behaviors regarding TCS use

\begin{tabular}{|c|c|c|c|c|c|}
\hline Fears and beliefs & Category & $\begin{array}{l}\text { I completely } \\
\text { disagree }\end{array}$ & $\begin{array}{l}\text { I don't } \\
\text { really agree }\end{array}$ & $\begin{array}{l}\text { I agree to a } \\
\text { certain extent }\end{array}$ & $\begin{array}{l}\text { I completely } \\
\text { agree }\end{array}$ \\
\hline TCS are effective over a short time period & $E$ & $12(4 \%)$ & $25(9 \%)$ & $84(30 \%)$ & $155(56 \%)$ \\
\hline TCS are effective over a long time period & $\mathrm{E}$ & $81(30 \%)$ & $58(21 \%)$ & $100(37 \%)$ & $33(12 \%)$ \\
\hline TCS pass into the bloodstream & $S$ & $66(25 \%)$ & $40(15 \%)$ & $92(35 \%)$ & $67(25 \%)$ \\
\hline TCS can lead to infections & $S$ & $147(56 \%)$ & $55(21 \%)$ & $40(15 \%)$ & $22(8 \%)$ \\
\hline TCS make you fat & S & $120(44 \%)$ & $40(15 \%)$ & $69(25 \%)$ & $42(15 \%)$ \\
\hline TCS damage your skin & S & $59(22 \%)$ & $44(16 \%)$ & $104(38 \%)$ & $65(24 \%)$ \\
\hline TCS will affect my future health & $\mathrm{S}$ & $93(35 \%)$ & $51(19 \%)$ & $90(33 \%)$ & $35(13 \%)$ \\
\hline There is a dependency risk & S & $90(33 \%)$ & $35(13 \%)$ & $84(31 \%)$ & $62(23 \%)$ \\
\hline I can become resistant to TCS & $\mathrm{S}$ & $42(16 \%)$ & $44(17 \%)$ & $107(40 \%)$ & $72(27 \%)$ \\
\hline TCS become inefficient over time & $E$ & $31(12 \%)$ & $39(14 \%)$ & $110(41 \%)$ & $89(33 \%)$ \\
\hline TCS calm symptoms but don't treat the cause & $E$ & $24(9 \%)$ & $25(9 \%)$ & $67(24 \%)$ & $159(58 \%)$ \\
\hline TCS make eczema worse & $E$ & $152(57 \%)$ & $58(22 \%)$ & $43(16 \%)$ & $15(6 \%)$ \\
\hline $\begin{array}{l}\text { TCS stop the eczema from coming up to the } \\
\text { surface of the skin }\end{array}$ & $\mathrm{E}$ & $33(12 \%)$ & $37(14 \%)$ & $72(27 \%)$ & $129(48 \%)$ \\
\hline TCS can lead to asthma & $\mathrm{S}$ & $181(72 \%)$ & $36(14 \%)$ & $29(11 \%)$ & $7(3 \%)$ \\
\hline $\begin{array}{l}\text { I don't know of any side-effects but I'm still } \\
\text { afraid of TCS }\end{array}$ & $\mathrm{S}$ & $43(16 \%)$ & $43(16 \%)$ & $102(38 \%)$ & $82(30 \%)$ \\
\hline TCS are more dangerous than CS in tablet form & $\mathrm{S}$ & $177(66 \%)$ & $37(14 \%)$ & $35(13 \%)$ & $18(7 \%)$ \\
\hline TCS treatment takes time and effort & $\mathrm{E}$ & $89(32 \%)$ & $74(27 \%)$ & $73(27 \%)$ & $38(14 \%)$ \\
\hline TCS treatment is complicated & Q & $157(58 \%)$ & $57(21 \%)$ & $38(14 \%)$ & $19(7 \%)$ \\
\hline TCS treatment helps me improve my quality of life & Q & $26(9 \%)$ & $27(10 \%)$ & $122(44 \%)$ & $100(36 \%)$ \\
\hline TCS increase my well-being & Q & $36(13 \%)$ & $31(11 \%)$ & $115(42 \%)$ & $91(33 \%)$ \\
\hline The advantages of TCS use outweigh the disadvantages & Q & $23(8 \%)$ & $44(16 \%)$ & $120(44 \%)$ & $87(32 \%)$ \\
\hline Behaviors regarding TCS treatment & & Never & Sometimes & Often & Always \\
\hline I'm afraid of applying too much cream & $\mathrm{S}$ & $76(29 \%)$ & $114(44 \%)$ & $58(22 \%)$ & $11(4 \%)$ \\
\hline I'm afraid of using the cream for too long & $\mathrm{S}$ & $49(19 \%)$ & $104(40 \%)$ & $77(30 \%)$ & $28(11 \%)$ \\
\hline $\begin{array}{l}\text { I'm afraid of putting cream on certain zones like the eyelids, } \\
\text { where the skin is thinner }\end{array}$ & $\mathrm{S}$ & $47(18 \%)$ & $70(27 \%)$ & $71(27 \%)$ & $73(28 \%)$ \\
\hline $\begin{array}{l}\text { It's more dangerous to use TCS on children than } \\
\text { on adults }\end{array}$ & $\mathrm{S}$ & $42(16 \%)$ & $72(28 \%)$ & $75(29 \%)$ & $72(28 \%)$ \\
\hline $\begin{array}{l}\text { If the doctor prescribed TCS then I would apply } \\
\text { the prescription }\end{array}$ & C & $31(12 \%)$ & $67(26 \%)$ & $53(20 \%)$ & $109(42 \%)$ \\
\hline I wait as long as I can before applying the treatment & C & $72(27 \%)$ & $70(27 \%)$ & $64(24 \%)$ & $56(21 \%)$ \\
\hline I stop the treatment as soon as I can & C & $34(13 \%)$ & $51(19 \%)$ & $87(33 \%)$ & $90(34 \%)$ \\
\hline I am careful to rub the cream in well when I apply it & $\mathrm{S}$ & $11(4 \%)$ & $27(10 \%)$ & $71(27 \%)$ & $151(58 \%)$ \\
\hline I avoid putting TCS on my child's hands & $\mathrm{S}$ & $78(30 \%)$ & $46(18 \%)$ & $32(12 \%)$ & $102(40 \%)$ \\
\hline I need reassurance about TCS & $\mathrm{S}$ & $44(17 \%)$ & $72(27 \%)$ & $61(23 \%)$ & 87 (33\%) \\
\hline
\end{tabular}

$E$ efficacy, $S$ safety, $Q$ quality of life, $C$ compliance

a reduction of compliance may cause prolonged and frequent relapses, which reduce trust in the treatment, thus further decreasing compliance.

Several studies highlighted the important role of the patient-doctor relationship in order to reduce fear of TCS $[7,11,14-16]$. We only investigated the effect of need of reassurance from the patient's doctor on TCS fear, and did not find any association. Nevertheless, as, according to our results, corticophobia is specifically directed towards treatment safety, it is mandatory that family pediatricians and general physicians dedicate a consistent time of the visit to identifying the patients' fear of TCS, in order to address misconceptions, thus improving the families' trust and compliance through evidence-based information.

Interestingly, $82 \%$ of our population was under TCS treatment, demonstrating that, despite fear, the parents 
were compliant to the prescription of their caregivers. Nevertheless, it is not possible to prove whether the use of TCS was adequate.

A large proportion of participants (two thirds) had received a therapeutic education for the management of atopic dermatitis. However, therapeutic education did not seem to affect fear of TCS among participants. In Italy, a therapeutic patient education program has been introduced in the last 5-10 years, in the third-level centers participating in the study. This education program aims at informing the families of pediatric patients about the disease course and at empowering them towards an autonomous therapeutic management of the disease [21]. The therapeutic education includes information on the appropriate modalities for applying topical products and on the use of distraction techniques aimed at creating a relaxing environment and at transforming the dressing moment into a pleasant interaction between the child and his parent [22-24]; no specific information is actually given on the safety profile of TCS. This may explain the lack of association between therapeutic education and TCS fear. Therapeutic education sessions could actually be excellent contexts for addressing TCS fear with participating families, thus improving their knowledge on safety and effectiveness of new generation TCS, with a subsequent, possible reduction of TCS fear.

The present study has several limitations. The main limitation concerns selection bias. The patients were enrolled from amongst those presenting to the pediatric dermatology outpatient clinics of the above mentioned hospitals. Nevertheless, this is a multicenter study involving hospitals that are located in different Italian regions, therefore the sample should be sufficiently representative of the Italian population of pediatric patients with AD. Moreover, only a very limited number of families refused to answer to the questionnaire, nevertheless we cannot exclude that patients whose parents refused to answer to the questionnaire differed in terms of age and sex from those that agreed to enrolment. Another limitation concerns the score used to assess TCS phobia. We adopted the score proposed by Aubert-Wastiaux [7]. The same score subsequently informed the production of a newer scale [25], which had good psychometric properties, but was not available at the time of our study. The adoption of such scale might have yielded more precise results.

\section{Conclusion}

$\mathrm{AD}$ is a chronic disorder and its treatment, mainly based on topical agents, is a long-term "therapeutic management", rather than a common therapy. Awareness of $\mathrm{AD}$ treatments' side effects is crucial, nevertheless, truths and misconceptions regarding this issue should be precisely addressed in order to ensure compliance. A specific educational program should follow a holistic approach and establish a strong relationship between the patient's family and caregivers. In fact, the results of our study prove the need of implementing and focusing the therapeutic education on the use of TCS and to spread it to all professionals involved in the management of AD. It is mandatory that caregivers dedicate time to inform parents about the safety of the new generation products, whose main advantage is a clearly improved risk/benefit ratio.

\section{Additional file}

Additional file 1: Univariate and multivariate analysis results (dependent variable: TCS fear). (DOCX $22 \mathrm{~kb}$ )

\section{Abbreviations}

AD: Atopic dermatitis; DLQI: Dermatology life quality index; SCORAD: Scoring atopic dermatitis; TCS: Topical corticosteroids; VAS: Visual analog scale

\section{Acknowledgements}

We would like to thank Mrs Lavinia Serra for her valuable logistic help and Dr. Emanuela Carloni for her valuable contribute to the statistical analysis.

\section{Funding}

No funding.

\section{Availability of data and materials}

The datasets generated during and/or analysed during the current study are not publicly available due to hospital research policy and lack of consent from those interviewed. Aggregate analyses different from those presented in the article are however available on reasonable request to the corresponding author.

\section{Authors' contributions}

MEA, FG and AD wrote the article; IN, FA and CM conceived the study; LG, $\mathrm{OA}, \mathrm{CO}$ and SG contributed to patient enrolment and data management; $\mathrm{MM}$, and EC revised the scientific literature and designed the questionnaire; GR, OS and ABF critically revised the article. All authors read and approved the final manuscript.

\section{Competing interests}

The authors declare that they have no competing interests.

\section{Consent to publication}

Not applicable.

\section{Ethics approval and consent to participate}

The study was approved by the Bambino Gesù Children's Hospital Ethical Committee (protocol N. 577_OPBG_2013). An informed consent to participation in the study was signed by parents at enrolment.

\section{Author details}

${ }^{1}$ Pediatric Dermatology Unit, Bambino Gesù Children's Hospital, IRCCS, Rome, Italy. ${ }^{2}$ Multifactorial Disease and Complex Phenotype Research Area, Bambino Gesù Children's Hospital IRCCS, Rome, Italy. ${ }^{3}$ Department of Medical and Surgical Sciences, Pediatric Unit, S. Orsola-Malpighi Hospital - University of Bologna, Bologna, Italy. ${ }^{4}$ Pediatric Dermatology, AORN Santobono-Pausilipon, Naples, Italy. ${ }^{5}$ Dermatology Unit, Istituto Giannina Gaslini, Genoa, Italy. ${ }^{6}$ Department of Medicine, Pediatric Dermatology Unit, University of Padua, Padua, Italy. ${ }^{7}$ Department of Medicine, Unit of Pediatric Dermatology, ARNAS Civico, Palermo, Italy. ${ }^{8}$ Dermatology Unit, M. Bufalini Hospital, Cesena, Italy. ${ }^{9}$ Department of Clinical and Molecular Sciences, Clinic of Dermatology, Università Politecnica delle Marche, Ancona, Italy. ${ }^{10}$ Dermatology Unit, San Luca Hospital, ASL 2, Lucca, Italy. ${ }^{11}$ Division of Dermatology, Department of Specialised, Experimental and Diagnostic Medicine, University of Bologna, S. Orsola-Malpighi Hospital, Bologna, Italy.

Received: 9 August 2016 Accepted: 14 January 2017

Published online: 28 February 2017 


\section{References}

1. Deckers IA, McLean S, Linssen S, Mommers M, van Schayck CP, Sheikh A. Investigating international time trends in the incidence and prevalence of atopic eczema 1990-2010: a systematic review of epidemiological studies. PLoS One. 2012;7:7.

2. Boguniewicz M, Leung DY. Atopic dermatitis: a disease of altered skin barrier and immune dysregulation. Immunol Rev. 2011;242:1.

3. Leung DY. New insights into atopic dermatitis: role of skin barrier and immune dysregulation. Allergol Int. 2013;62:2.

4. Wolter S, Price HN. Atopic dermatitis. Pediatr Clin North Am. 2014;61:2.

5. Charman C, Williams H. The use of corticosteroids and corticosteroid phobia in atopic dermatitis. Clin Dermatol. 2003;21:3.

6. Furue M, Terao H, Rikihisa W, Urabe K, Kinukawa N, Nose Y, et al. Clinical dose and adverse effects of topical steroids in daily management of atopic dermatitis. Br J Dermatol. 2003:148:1.

7. Aubert-Wastiaux H, Moret L, Le Rhun A, Fontenoy AM, Nguyen JM, Leux C, et al. Topical corticosteroid phobia in atopic dermatitis: a study of its nature, origins and frequency. Br J Dermatol. 2011;165:4.

8. Kojima R, Fujiwara T, Matsuda A, Narita M, Matsubara O, Nonoyama S, et al. Factors associated with steroid phobia in caregivers of children with atopic dermatitis. Pediatr Dermatol. 2013;30:1.

9. Hanifin J, Rajka G. Diagnostic features of atopic dermatitis. Acta Derm Venereol (Stockh). 1980;92:44-47.

10. Severity scoring of atopic dermatitis: The SCORAD index. consensus report of the european task force on atopic dermatitis. Dermatology. 1993;186(1):23-31.

11. Fischer G. Compliance problems in paediatric atopic eczema. Australas Dermatol. 1996;37 Suppl 1:S10-3.

12. Ohya $Y$, Williams H, Steptoe A, Saito H, likura Y, Anderson R, et al. Psychosocial factors and adherence to treatment advice in childhood atopic dermatitis. J Invest Dermatol. 2001;117:4.

13. Beattie PE, Lewis-Jones MS. Parental knowledge of topical therapies in the treatment of childhood atopic dermatitis. Clin Exp Dermatol. 2003;28:5.

14. Smith SD, Hong E, Fearns S, Blaszczynski A, Fischer G. Corticosteroid phobia and other confounders in the treatment of childhood atopic dermatitis explored using parent focus groups. Australas J Dermatol. 2010;51:3.

15. Charman CR, Morris AD, Williams HC. Topical corticosteroid phobia in patients with atopic eczema. Br J Dermatol. 2000;142:5

16. Hon KL, Kam WY, Leung TF, Lam MC, Wong KY, Lee KC, et al. Steroid fears in children with eczema. Acta Paediatr. 2006:95:11.

17. West DP, Worobec S, Solomon LM. Pharmacology and toxicology of infant skin. J Invest Dermatol. 1981;76:3.

18. Turpeinen M. Influence of age and severity of dermatitis on the percutaneous absorption of hydrocortisone in children. Br J Dermatol. 1988;118:4.

19. Brazzini B, Pimpinelli N. New and established topical corticosteroids in dermatology: clinical pharmacology and therapeutic use. Am J Clin Dermatol. 2002;3:1

20. Callen J, Chamlin S, Eichenfield LF, Ellis C, Girardi M, Goldfarb M, et al. A systematic review of the safety of topical therapies for atopic dermatitis. $\mathrm{Br}\rfloor$ Dermatol. 2007;156:2.

21. Ricci G, Bendandi B, Aiazzi R, Patrizi A, Masi M. Three years of italian experience of an educational program for parents of young children affected by atopic dermatitis: Improving knowledge produces lower anxiety levels in parents of children with atopic dermatitis. Pediatr Dermatol. 2009;26:1.

22. Chavigny JM. The role of therapeutic education in the treatment of atopic dermatitis in children. Ann Dermatol Venereol. 2005;132 Spec No 1:1S116-20.

23. Barbarot S, Bernier C, Deleuran M, De Raeve L, Eichenfield L, El Hachem M, et al. Therapeutic patient education in children with atopic dermatitis: position paper on objectives and recommendations. Pediatr Dermatol. 2013;30:2.

24. Ersser SJ, Cowdell F, Latter S, Gardiner E, Flohr C, Thompson AR, et al. Psychological and educational interventions for atopic eczema in children. Cochrane Database Syst Rev. 2014:1:CD004054

25. Moret L, Anthoine E, Aubert-Wastiaux H, Le Rhun A, Leux C, MazereeuwHautier J, et al. TOPICOPO: a new scale evaluating topical corticosteroid phobia among atopic dermatitis outpatients and their parents. PLoS One. 2013;8:e76493.

\section{Submit your next manuscript to BioMed Central and we will help you at every step:}

- We accept pre-submission inquiries

- Our selector tool helps you to find the most relevant journal

- We provide round the clock customer support

- Convenient online submission

- Thorough peer review

- Inclusion in PubMed and all major indexing services

- Maximum visibility for your research

Submit your manuscript at www.biomedcentral.com/submit

) Biomed Central 